\title{
Caffeine Reduces Low-Frequency Delta Activity in the Human Sleep EEG
}

Hans Peter Landolt, Derk-Jan Dijk, Ph.D., Stephanie E. Gaus, and Alexander A. Borbély, M.D.

In view of the hypothesis that adenosine is involved in sleep regulation, the effects of the adenosine antagonist caffeine on sleep and sleep EEG were investigated in eight young males. Compared to the placebo condition, caffeine $(100 \mathrm{mg})$ administered at bedtime prolonged sleep latency and reduced sleep efficiency and stage 4 of non-rapid eye movement sleep (NREMS).

Electroencephalographic slow-wave activity (SWA, spectral power density in the $0.75-4.5-\mathrm{Hz}$ band) was reduced, whereas power density in the spindle frequency range was slightly enhanced. The suppression of SWA was limited to the first NREMS episode. Caffeine reduced the power density mainly in the lowest delta band, in contrast to the changes during physiological sleep that encompass both the delta and theta bands. Caffeine levels in saliva, assessed in a separate experiment, decreased from $7.5 \mu \mathrm{mol} / \mathrm{l}$ in the first hour of sleep to $3.5 \mu \mathrm{mol} / \mathrm{l}$ in the seventh hour. In the night following caffeine administration, stage 4 sleep had reverted to the baseline level, but sleep latency was still increased, and stage 2 sleep, as well as SWA in the first NREMS episode, were reduced. The data show that even a low dose of caffeine affects the sleep EEG. However, the effects of caffeine did not completely mimic the spectral changes observed during physiological sleep. [Neuropsychopharmacology 12:229-238, 1995]
KEY WORDS: Spectral analysis; Adenosine; Slow-wave sleep; REM sleep; Sleep homeostasis

Caffeine is a widely used stimulant, and its effects on sleep have been documented in many studies (for a review, see Snel 1993). It is well established that sleep latency is prolonged and wakefulness after sleep onset is enhanced after the intake of caffeine. In most studies slow-wave sleep [SWS, i.e., visually scored stages $3+$ 4 of non-rapid eye movement (NREM) sleep] was found to be suppressed. For rapid eye movement (REM) sleep, both a reduction and an increase have been reported (Karacan et al. 1976; Nicholson and Stone 1980).

The effects of caffeine at concentrations typically

From the Institute of Pharmacology, University of Zürich, Zürich, Switzerland.

Address all correspondence to: A.A. Borbély, Institute of Pharmacology, University of Zürich, Winterthurerstrasse 190, CH 8057 Zürich, Switzerland.

Received March 11, 1994; revised July 1, 1994; accepted October 2, 1994. reached after the consumption of a caffeine-containing beverage are generally believed to be mediated by $\mathrm{A} 1$ and A2 adenosine receptors (Biaggioni et al. 1991; Nehlig et al. 1992; Daly 1993; Sawynok and Yaksh 1993; Snyder et al. 1981). At micromolar concentrations, caffeine is an antagonist at both $\mathrm{A} 1$ and $\mathrm{A} 2$ receptors (Daly 1993). Animal studies have revealed that adenosine agonists prolong NREM sleep and preferentially enhance its deep stages (i.e., slow-wave sleep 2) in different species (Haulica et al. 1973; Marley and Nistico 1972; Radulovacki et al. 1982, 1983; Virus et al. 1990). In the rat, $\mathrm{A} 1$ agonists selectively enhanced $\mathrm{EEG}$ power density in the delta and theta frequencies (Benington et al. 1993), an effect that is similar to the effect of sleep deprivation (Borbély et al. 1984; Tobler and Borbély 1990). Based on these data and on neurophysiological evidence, it has been proposed that adenosine plays a key role in physiological sleep regulation (Benington et al. 1993; Radulovacki 1993; Rainnie et al. 1994).

In humans the homeostatic facet of sleep regulation, and more specifically the effect of prior wakefulness and prior sleep on the sleep EEG, has been inves- 
tigated by spectral analysis in a number of studies. It was shown that EEG power density of delta (0.75-4.5 $\mathrm{Hz}$ ) and theta frequencies $(6.25-9 \mathrm{~Hz})$ are enhanced after an extension of prior wakefulness, whereas power density in the frequency range of sleep spindles $(12.25-15 \mathrm{~Hz})$ is reduced (Borbély et al. 1981; Dijk et al. 1987a, 1990a). The reverse pattern can be observed during the decline of "sleep pressure" in the course of sleep (Borbély et al. 1981; Dijk et al. 1990b). As yet, no pharmacological agent has been found to mimic this "spectral fingerprint" of sleep homeostasis (Borbély et al. 1985; Brunner et al. 1991; Dijk et al. 1989, 1992; Steiger et al. 1993; Trachsel et al. 1990). If adenosine plays a key role in the physiology of sleep regulation, an adenosine receptor antagonist may be expected to suppress power density in the delta and theta frequencies and enhance power density in the frequency range of sleep spindles. The present study was prompted by the fact that no human sleep EEG spectra are available for compounds affecting the adenosine receptor. We selected caffeine as the most widely used adenosine receptor antagonist. To minimize sleep disruption (i.e., prolongation of sleep latency, increase of intermittent wakefulness), caffeine was administered immediately prior to bedtime at a dose that is at the lower limit of the effective dose range. Since it had been previously demonstrated that hypnotics, even if they have a short elimination half-life, may affect the sleep EEG after more than 24 hours (Borbély et al. 1983), the analysis was extended to the first drug-free postdrug night.

\section{METHODS}

\section{Subjects and Study Protocol}

Eight males (mean age: $23.3 \pm 0.3$ years SEM; range 20-25 years) recruited from the student population of the University of Zürich and the Swiss Federal Institute of Technology, were paid for participation in the study. Written informed consent was obtained prior to the study, which was approved by the local ethical committee for research on human subjects. Subjects' medical history, current health status, and subjective sleep quality were assessed by questionnaires. No sleep disturbances were reported. The subjects were all nonsmokers, and their habitual alcohol intake was less than five drinks per week. They were asked to abstain from alcohol during the study. The subjects reported a habitual consumption of one to three caffeinated beverages per day. A caffeine $\log$ in the week prior to the study revealed an intake of $1.4 \pm 0.1$ (SEM) caffeinated drinks per day. During this week subjects were instructed to keep a regular sleep-wake pattern with sleep scheduled from 2300 to 0700 hours. During the weekend they were allowed to deviate from this schedule by not more than 1 hour. Compliance with this instruction was verified by inspection of the rest-activity plots obtained by continuous recording of wrist-activity from the nondominant arm.

Subjects slept in the laboratory on four consecutive nights (Monday to Thursday) between 2300 and 0700 hours. Since dependence on caffeine can appear with even very slight doses and caffeine withdrawal can cause numerous symptoms (Griffiths et al. 1990; see Nehlig et al. 1992, for a recent review), it was important to avoid withdrawal effects. Therefore, the subjects were allowed to continue their habitual caffeine intake in the morning throughout the experiment, which consisted of one cup (seven subjects) or two cups (one subject) of coffee at breakfast. Immediately prior to the scheduled sleep episodes, they received a capsule. On the third night this capsule contained $100 \mathrm{mg}$ of caffeine (caffeine anhydrous; manufacturer: Siegfried Ltd., Zofingen, Switzerland) and mannitol (manufacturer: Siegfried Ltd., Zofingen, Switzerland), whereas on all other nights it contained only mannitol. The subjects were blind to the treatment.

Subjective sleep quality was assessed 15 minutes after awakening by a questionnaire and a $100-\mathrm{mm}$ visual analogue scale (Brunner et al. 1991).

\section{Polygraphic Recordings/EEG and ECG Analysis}

During all sleep episodes the EEG, submental electromyogram (EMG), electrooculogram (EOG), and electrocardiogram (ECG) were recorded on Grass polygraphs (model 78E and 78D; Quincy, MA, USA). The EEG electrodes were placed at the locations C3, F3, P3, and O1, according to the 10-20 system (Jasper 1958). All EEG signals were recorded against the right mastoid (A2). For the EEG signals the half-amplitude lowfrequency cutoff was set at $0.1 \mathrm{~Hz}$. The EEG signals were subjected to low-pass filtering in different steps, the combined action of which resulted in a 3- $\mathrm{dB}$ attenuation at $27 \mathrm{~Hz}$. Signals were analogue-to-digital (A/D) converted with a sampling rate of $256 \mathrm{~Hz}$ (12-bit resolution), digitally low-pass filtered (3-dB attenuation at $25 \mathrm{~Hz}$ ), and stored on a PC with $128 \mathrm{~Hz}$. All EEGs were subjected to a Fast Fourier transform (FFT) routine. The epoch length was $4 \mathrm{sec}$, and a $10 \%$ tapered-cosine window was applied. Data reduction of power spectra was achieved by omitting bins above $25 \mathrm{~Hz}$ and by averaging power spectra over two $(0.25-5 \mathrm{~Hz})$ or four $(5.25-25$ $\mathrm{Hz}$ ) adjacent $0.25-\mathrm{Hz}$ bins. Records from the first night (adaptation) were not evaluated. The polygraphic recordings of nights 2 to 4 were scored visually for 20sec epochs on a PC according to standard criteria (Rechtschaffen and Kales 1968). All 4-sec epochs with artifacts were visually identified and eliminated. Power spectra were calculated per sleep stage, NREM-REM sleep cycle or time interval. Cardiac beat-to-beat intervals, determined as the time between successive $R$ waves, were 
detected off-line by a level-crossing algorithm. An artifact-detection routine was applied that identified epochs in which the variability exceeded a preset value of the amplitude or R-R intervals. These epochs were visually inspected and either corrected or eliminated.

\section{Caffeine Concentration in Saliva}

Previous studies have shown a close association between saliva and plasma levels of caffeine. After oral administration of 100 to $300 \mathrm{mg}$, the ratio between the concentration in saliva and plasma was approximately 0.8 (Haeckel 1990; Zylber-Katz et al. 1984). Prior to all sleep episodes a saliva sample was collected at 2245 hours and stored immediately at $-20^{\circ} \mathrm{C}$. These samples were assayed for caffeine with a homogenous enzyme-immunoassay $\left(\mathrm{Emit}^{\circledR}{ }^{\circledR}\right.$-Caffeine Test, Syva Company, Palo Alto, CA; Oellerich 1980). The kinetics of caffeine concentration in saliva in the course of the sleep episode was assessed in a separate experiment. Eight male nonsmoking subjects (mean age: $23.2 \mathrm{y} \pm 0.5 \mathrm{SEM}$; range 20-25 years), seven of whom participated in the sleep study, came to the laboratory at approximately 2200 hours. After collection of a saliva sample at 2245 hours, $100 \mathrm{mg}$ caffeine was administered at 2255 hours. After collection of an additional saliva sample, subjects went to bed at 2300 hours. They were awakened at midnight, 0200,0400 , and 0600 hours for collection of saliva samples.

\section{Statistics}

Statistical significance of effects was assessed with analyses of variance (ANOVAs) for repeated measures. Contrasts were tested by $t$-tests. To approximate a normal distribution, the variables expressed as percentage of control values as well as sleep latency were logtransformed prior to statistical tests. A more detailed description of the statistics is provided in the text and the figure legends.

\section{RESULTS}

\section{Caffeine Concentration in Saliva}

The concentration of caffeine in saliva samples collected 15 minutes prior to bedtime of the baseline night was below the limit of detection $(1 \mu \mathrm{mol} / \mathrm{L})$ in six subjects and 1.5 and $2.4 \mu \mathrm{mol} / \mathrm{L}$ in the two other subjects. Prior to taking caffeine, concentrations were below the detection limit in five subjects, $2.4 \mu \mathrm{mol} / \mathrm{L}$ in two subjects and $4 \mu \mathrm{mol} / \mathrm{L}$ in one subject. Caffeine concentrations on the last night were below the detection level in four subjects and 1.4, 1.5, 2.7, and $3.6 \mu \mathrm{mol} / \mathrm{L}$ in the others.

The average time course of caffeine concentration in saliva during the sleep episode exhibited a maximum
1 hour after intake (Figure 1). At 0600 hours (i.e., 7 hours after intake), the caffeine level had decreased to an average concentration of $3.5 \mu \mathrm{mol} / \mathrm{L}$.

\section{Heart Rate}

The ANOVA did not reveal a significant effect of treatment on heart rate (see Table 1).

\section{Subjective Sleep Quality}

No significant effects of the treatment were detected on the subjective sleep quality parameters, including subjective sleep latency and the perceived number and duration of awakenings at night (data not shown).

\section{Sleep Parameters Derived from Visual Scoring}

Caffeine intake at 2300 hours resulted in a significantly longer time to fall asleep (Table 2), while total sleep time, sleep efficiency, and stage 4 sleep (Table 1 ) were significantly reduced. The reduction of stage 4 and SWS was statistically significant only in the first NREM sleep episode when there was more time spent in stage 1 sleep compared to baseline.

On the fourth night (i.e., postcaffeine sleep episode) the latency to sleep onset was still prolonged (Table 2) whereas stage 4 sleep computed for the entire sleep episode and for the first NREM sleep episode had reverted to the baseline level (Table 1). Sleep efficiency and stage 2 sleep were still below baseline in the postcaffeine night. No significant treatment effects on the duration of REM sleep episodes and NREM-REM sleep cycles were observed.

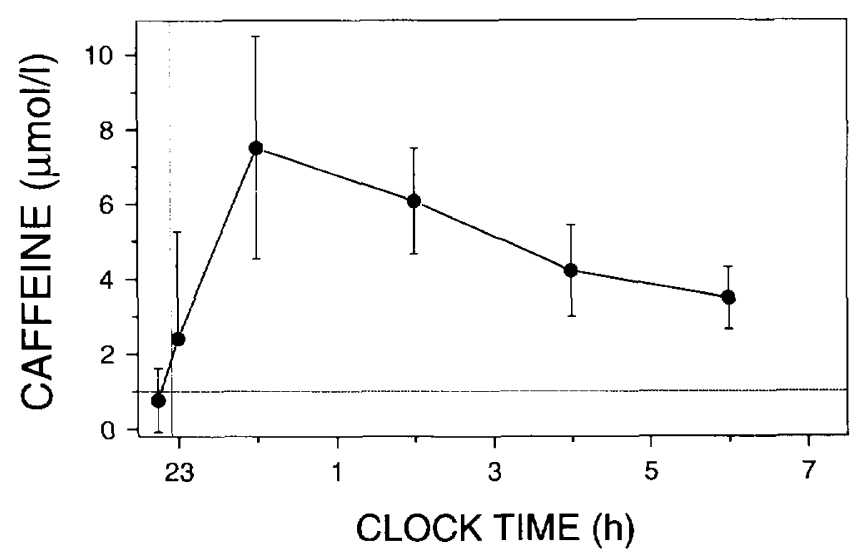

Figure 1. Time course of caffeine concentration in saliva. Vertical bars represent one standard error of the mean (SEM; $n=$ $8)$. Samples in which caffeine levels were below the detection limit ( $1 \mu \mathrm{mol} / \mathrm{L}$; horizontal line) were assigned a value of zero. 
Table 1. Visually Scored Sleep Stages (minutes), SWA $\left(\mu \mathrm{V}^{2} / \mathrm{Hz}\right)$, and heart rate (bpm)

\begin{tabular}{|c|c|c|c|c|c|c|c|c|c|}
\hline \multirow[b]{2}{*}{ Parameter } & \multirow[b]{2}{*}{ Condition } & \multirow{2}{*}{$\begin{array}{c}\text { Total Sleep } \\
\text { Episode }\end{array}$} & \multicolumn{4}{|c|}{ NREM-REM Cycle } & \multirow{2}{*}{$\begin{array}{l}\text { Treatment } \\
F(2,14)(p) \\
\end{array}$} & \multirow{2}{*}{$\begin{array}{c}\text { Cycle } \\
F(3,21)(p)\end{array}$} & \multirow{2}{*}{$\begin{array}{c}\text { Treatment } \\
\text { Cycle } \\
F(6,42)(p) \\
\end{array}$} \\
\hline & & & $\mathbf{1}$ & 2 & 3 & 4 & & & \\
\hline W & $\begin{array}{l}\text { B } \\
\text { C } \\
\text { PC }\end{array}$ & $\begin{array}{l}3.1(1.0) \\
7.1(2.7) \\
4.2(1.6)\end{array}$ & $\begin{array}{l}0.3(0.3) \\
2.0(1.4) \\
0.2(0.1)\end{array}$ & $\begin{array}{l}0.5(0.3) \\
0.5(0.2) \\
0.3(0.2)\end{array}$ & $\begin{array}{l}0.5(0.4) \\
3.3(2.4) \\
2.4(1.2)\end{array}$ & $\begin{array}{l}0.6(0.3) \\
0.9(0.4) \\
1.0(0.5)\end{array}$ & $1.76(.22)$ & $1.67(.22)$ & $0.64(.52)$ \\
\hline 1 & $\begin{array}{l}\text { B } \\
\text { C } \\
\text { PC }\end{array}$ & $\begin{array}{l}27.1(2.9) \\
36.9(5.7) \\
31.3(3.7)\end{array}$ & $\begin{array}{l}2.5(0.8) \\
7.5(2.3)^{a} \\
5.4(2.0)\end{array}$ & $\begin{array}{l}5.3(1.1) \\
7.2(2.6) \\
4.7(0.9)\end{array}$ & $\begin{array}{l}6.1(1.4) \\
6.8(1.5) \\
9.6(1.7)\end{array}$ & $\begin{array}{l}5.8(1.5) \\
9.8(2.4) \\
9.2(2.4)\end{array}$ & $3.70(.06)$ & $1.88(.20)$ & $0.93(.43)$ \\
\hline 2 & $\begin{array}{c}B \\
C \\
P C\end{array}$ & $\begin{array}{l}197.0(13.6) \\
179.4(13.3) \\
169.7(11)^{a}\end{array}$ & $\begin{array}{l}19.2(7.8) \\
24.0(5.4) \\
23.7(5.8)\end{array}$ & $\begin{array}{l}36.5(4.8) \\
36.7(6.2) \\
26.4(3.2)\end{array}$ & $\begin{array}{l}49.2(4.6) \\
44.1(3.6) \\
58.9(7.5)\end{array}$ & $\begin{array}{l}49.6(5.1) \\
39.5(1.4) \\
34.9(4.3)\end{array}$ & $1.40(.28)$ & $11.00(<.01)$ & $4.01(.02)$ \\
\hline 3 & $\begin{array}{l}B \\
C \\
P C\end{array}$ & $\begin{array}{l}50.0(2.9) \\
48.9(4.4) \\
50.3(4.9)\end{array}$ & $\begin{array}{r}9.3(2.7) \\
11.4(2.1) \\
12.9(3.6)\end{array}$ & $\begin{array}{l}17.3(1.9) \\
14.7(2.3) \\
17.4(3.0)\end{array}$ & $\begin{array}{r}12.2(2.0) \\
10.9(2.2) \\
9.1(2.6)\end{array}$ & $\begin{array}{l}7.0(2.2) \\
7.0(1.6) \\
9.0(1.8)\end{array}$ & $0.36(.69)$ & $3.28(.06)$ & $0.86(.49)$ \\
\hline 4 & $\begin{array}{l}B \\
C \\
P C\end{array}$ & $\begin{array}{l}72.9(10.6) \\
62.5(10.5)^{a} \\
73.0(10.3)^{c}\end{array}$ & $\begin{array}{l}34.2(4.0) \\
25.2(3.3)^{b} \\
33.1(4.4)^{c}\end{array}$ & $\begin{array}{l}22.9(4.7) \\
22.2(4.9) \\
24.8(3.8)\end{array}$ & $\begin{array}{l}12.3(4.0) \\
9.8(3.0) \\
3.0(1.3)^{a, c}\end{array}$ & $\begin{array}{c}1.7(1.1) \\
2.1(1.0) \\
12.0(4.0)^{a, c}\end{array}$ & $7.83(<.01)$ & $40.34(<.01)$ & $3.17(.06)$ \\
\hline SWS & $\begin{array}{l}\text { B } \\
\mathrm{C} \\
\mathrm{PC}\end{array}$ & $\begin{array}{l}122.9(9.5) \\
111.4(14.1) \\
123.2(10.1)\end{array}$ & $\begin{array}{l}43.4(2.4) \\
36.5(3.7)^{a} \\
46.0(3.4)\end{array}$ & $\begin{array}{l}40.1(4.7) \\
36.9(5.6) \\
42.2(2.7)\end{array}$ & $\begin{array}{l}24.5(4.7) \\
20.7(4.0) \\
12.0(3.7)^{a, c}\end{array}$ & $\begin{array}{c}8.6(2.5) \\
9.1(2.4) \\
21.0(4.7)^{a, c}\end{array}$ & $4.58(.04)$ & $40.56(<.01)$ & $3.15(.04)$ \\
\hline REMS & $\begin{array}{l}\mathrm{B} \\
\mathrm{C} \\
\mathrm{PC}\end{array}$ & $\begin{array}{l}105.8(5.8) \\
113.4(2.9) \\
123.5(6.2)\end{array}$ & $\begin{array}{r}9.3(3.8) \\
11.5(1.6) \\
11.7(3.2)\end{array}$ & $\begin{array}{l}25.1(2.3) \\
28.9(5.7) \\
24.7(4.3)\end{array}$ & $\begin{array}{l}23.8(3.8) \\
32.5(4.4) \\
40.8(4.0)\end{array}$ & $\begin{array}{l}29.8(5.2) \\
32.0(4.4) \\
34.1(8.5)\end{array}$ & $3.02(0.12)$ & $10.56(<.01)$ & $0.72(.53)$ \\
\hline SWA & $\begin{array}{l}\text { B } \\
C \\
\text { PC }\end{array}$ & $\begin{array}{l}90.5(11.2) \\
80.1(10.8)^{a} \\
87.7(11.7)^{d}\end{array}$ & $\begin{array}{l}204.0(29.7) \\
137.2(16.6)^{b} \\
180.6(32.4)^{a}\end{array}$ & $\begin{array}{l}113.9(16.6) \\
113.6(20.7) \\
120.0(15.9)\end{array}$ & $\begin{array}{l}74.4(12.6) \\
64.4(10.6) \\
50.7(8.7)^{b, c}\end{array}$ & $\begin{array}{l}43.4(5.2) \\
41.7(6.4) \\
63.8(14.8)\end{array}$ & $8.97(<.01)$ & $33.19(<.01)$ & $4.52(0.03)$ \\
\hline MT & $\begin{array}{l}\mathrm{B} \\
\mathrm{C} \\
\mathrm{PC}\end{array}$ & $\begin{array}{l}13.3(1.0) \\
12.9(1.1) \\
13.0(0.6)\end{array}$ & $\begin{array}{l}1.2(0.4) \\
2.3(0.3) \\
2.1(0.4)\end{array}$ & $\begin{array}{l}2.9(0.4) \\
2.3(0.6) \\
2.5(0.3)\end{array}$ & $\begin{array}{l}3.5(0.4) \\
3.3(0.6) \\
4.4(0.5)\end{array}$ & $\begin{array}{l}3.0(0.4) \\
3.3(0.7) \\
2.9(0.6)\end{array}$ & $1.81(0.22)$ & $4.54(0.03)$ & $1.41(0.27)$ \\
\hline Cycle & $\begin{array}{l}\mathrm{B} \\
\mathrm{C} \\
\mathrm{PC}\end{array}$ & $\begin{array}{l}- \\
- \\
-\end{array}$ & $\begin{array}{l}75.9(11.1) \\
83.8(6.4) \\
89.1(10.6)\end{array}$ & $\begin{array}{l}110.3(7.7) \\
112.5(9.8) \\
100.8(5.7)\end{array}$ & $\begin{array}{l}107.5(8.3) \\
110.6(6.8) \\
128.1(9.3)\end{array}$ & $\begin{array}{c}97.4(11.1) \\
94.6(7.2) \\
103.1(10.7)\end{array}$ & $4.12(0.07)$ & $3.66(0.06)$ & $0.91(0.46)$ \\
\hline Heart rate & $\begin{array}{l}\mathrm{B} \\
\mathrm{C} \\
\mathrm{PC}\end{array}$ & $\begin{array}{l}52.0(2.1) \\
50.1(1.8) \\
50.1(2.1)\end{array}$ & $\begin{array}{l}53.2(2.5) \\
50.0(1.7) \\
51.1(2.3)\end{array}$ & $\begin{array}{l}51.9(2.1) \\
50.7(2.2) \\
49.9(2.5)\end{array}$ & $\begin{array}{l}51.8(2.1) \\
50.0(1.9) \\
49.8(2.1)\end{array}$ & $\begin{array}{l}51.8(2.2) \\
50.1(1.8) \\
48.8(2.1)\end{array}$ & $4.29(0.06)$ & $0.72(0.45)$ & $0.38(0.68)$ \\
\hline
\end{tabular}

Abbreviations: $\mathrm{W}=$ waking time after sleep onset; $\mathrm{B}=$ baseline sleep episode; $\mathrm{C}=$ caffeine sleep episode; $\mathrm{PC}=$ postcaffeine sleep episode; $1,2,3,4=$ NREM sleep stages $1-4 ;$ SWS $=$ slow-wave sleep; REMS = REM sleep; SWA = slow-wave activity; MT = movement time. Values are for means (SEM).

${ }_{a}^{a} p<.05$ Compared to baseline (paired $t$-test).

${ }^{b} p<.01$ Compared to baselines (paired $t$-test).

$c p \leqslant .05$ Compared to caffeine (paired $t$-test).

$d p<.01$ Compared to caffeine (paired $t$-test).

Table 2. Sleep Parameters (minutes)

\begin{tabular}{lcccc}
\hline Parameter & Baseline & Caffeine & Postcaffeine & \multicolumn{1}{c}{$\boldsymbol{F ( 2 , 1 4 ) ( p )}$} \\
\hline SL & $10.5(2.7)$ & $18.8(4.5)^{a}$ & $14.6(2.7)^{a}$ & $15.45(<.01)$ \\
RL & $65.6(7.9)$ & $69.8(6.6)$ & $74.3(7.8)$ & $2.66(.11)$ \\
TST & $452.9(2.2)$ & $441.1(5.2)^{b}$ & $447.6(2.9)$ & $4.79(.04)$ \\
SE & $94.0(0.4)$ & $91.6(1.0)^{b}$ & $92.9(0.6)^{b}$ & $4.84(.04)$ \\
SEP & $469.2(2.7)$ & $461.2(4.5)^{b}$ & $464.9(2.9)^{b}$ & $7.15(.02)$ \\
\hline
\end{tabular}

Baseline, Caffeine, and Postcaffeine refer to respective sleep episodes. Abbreviations: $\mathrm{SL}=$ sleep onset latency; RL = REM sleep latency; TST = total sleep time; $\mathrm{SE}=$ sleep efficiency; $\mathrm{SEP}=$ sleep episode. Values are for means (SEM).

${ }^{a} p<.01$ Compared to baseline (paired $t$-test)

${ }^{b} p<.05$ Compared to baseline (paired $t$-test) 
BASELINE

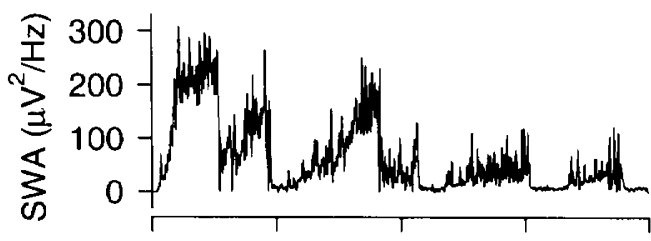

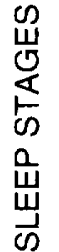

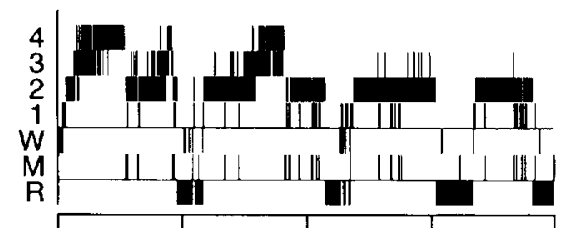

CAFFEINE
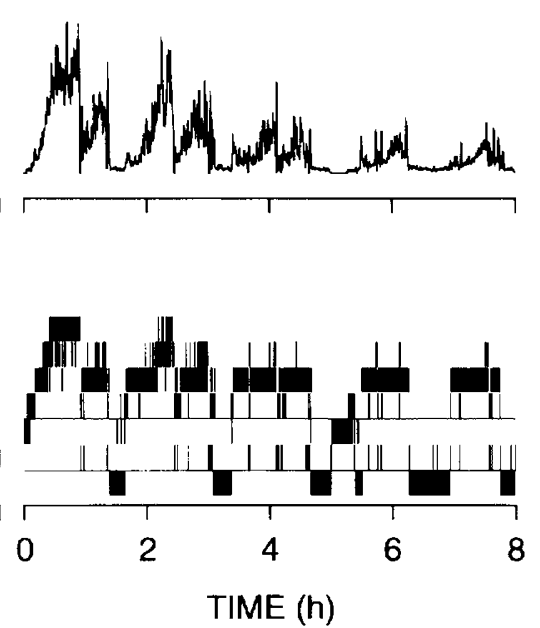

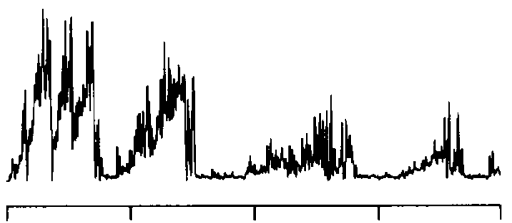

POST-CAFFEINE

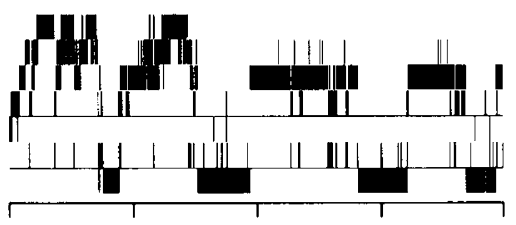

Figure 2. Slow-wave activity $(S W A)$ and sleep stages during a baseline sleep episode, a sleep episode starting immediately after intake of $100 \mathrm{mg}$ caffeine, and a sleep episode starting 24 hours after administration of a caffeine capsule. $W=$ wakefulness; $R=$ REM sleep; $1,2,3,4=$ NREM sleep stages $1-4 ; M=$ movement time.

BASELINE

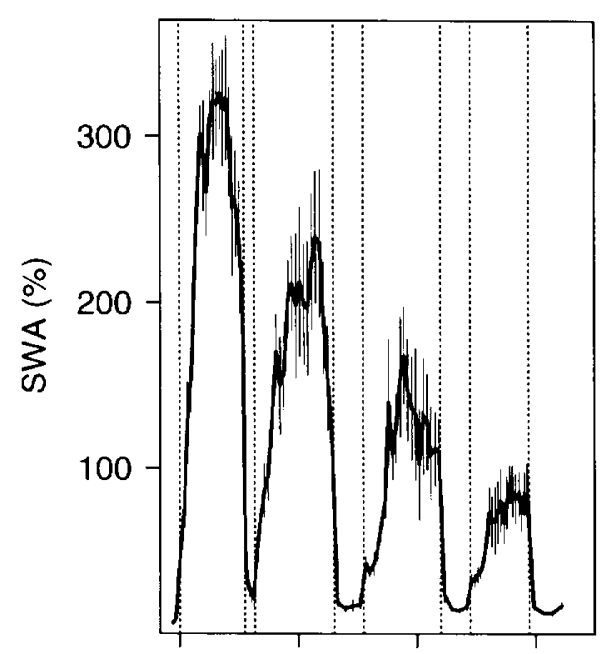

CAFFEINE

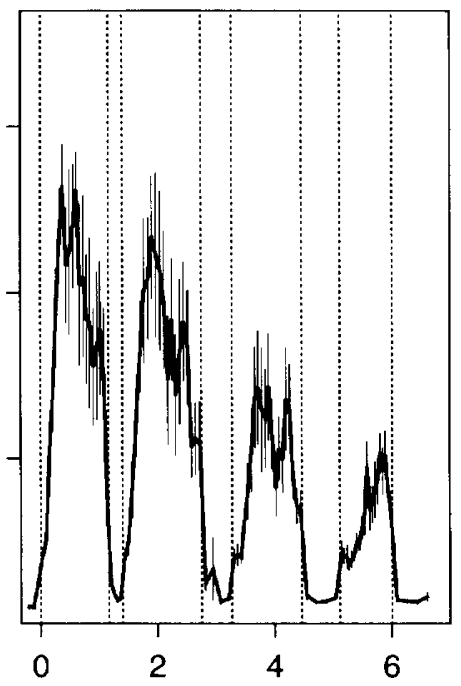

HOURS AFTER SLEEP ONSET
POST-CAFFEINE

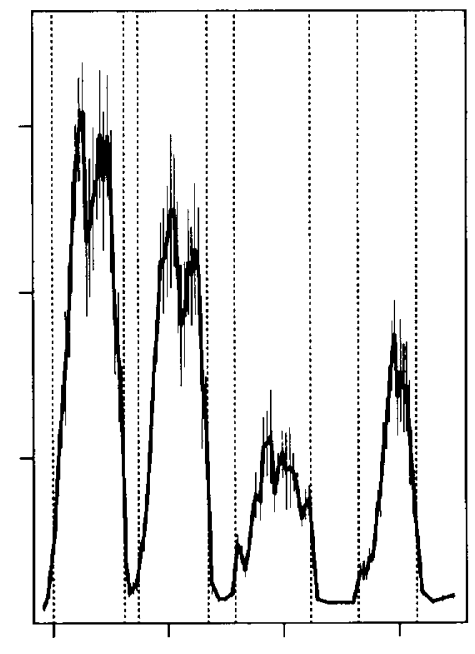

Figure 3. Dynamics of SWA averaged over eight subjects during the baseline, caffeine, and postcaffeine sleep episode (C3-A2 derivation). Data were aligned with respect to the onset and the end of a NREM sleep episode. In each subject SWA values were expressed relative to the average SWA value of baseline sleep. Individual NREM episodes were subdivided into 20 equal parts and REM episodes into 4 equal parts. Then the data were averaged across subjects. The SWA data are plotted against the average timing of NREM sleep episodes and REM sleep episodes (dotted vertical lines). 


\section{Slow-Wave Activity}

An example of the time course of sleep stages and slowwave activity (SWA, i.e., EEG power density, 0.75-4.5 $\mathrm{Hz}$ ) is shown in Figure 2. In this subject SWA was clearly reduced only in the first NREM sleep episode of the caffeine night. Average SWA data are summarized in Table 1. A repeated measures ANOVA showed a significant effect of the factors "cycle," "treatment," and their interaction. A significant reduction of SWA was present in the first NREM sleep episode as well as in the entire sleep episode of the caffeine night. In the postcaffeine night SWA was no longer different from baseline for the entire sleep episode but below baseline for NREM sleep episodes 1 and 3.

\section{Dynamics of SWA}

Analysis of the dynamics of SWA over consecutive NREM-REM sleep cycles demonstrated that caffeine had little effect on the interepisodic time course of SWA (Figure 3). A quantitative comparison of the evolution of SWA from 2 minutes prior to the NREM sleep episode to the furst 20 minutes of the episode revealed a reduced buildup rate of SWA in the first NREM sleep episode after intake of caffeine and 24 hours later. A repeated measures ANOVA showed a significant effect of the factors "condition" $[F(2,14)=9.26, p<.003]$ and "2-minute interval" $[F(10,70)=54.01, p<.0001]$. The SWA buildup was significantly reduced in the following time intervals (paired $t$-tests): 10 to 12 minutes ( $p<$ $.01), 14$ to 16 minutes ( $p<.01$ ), and 18 to 20 minutes $(p<.005)$ in the caffeine sleep episode, and 2 to 4 minutes $(p<.03)$ and 18 to 20 minutes $(p<.04)$ in the postcaffeine sleep episode. However, the buildup rate of SWA was significantly higher in the postcaffeine sleep episode compared to the caffeine sleep episode in the 4 - to 6 -minute interval $(p<.03)$. No significant differences in the buildup of SWA were detected in subsequent NREM sleep episodes.

\section{Changes of EEG Power Spectra over Consecutive NREM Sleep Episodes during Baseline and Caffeine Sleep Episodes}

The changes of EEG power spectra over consecutive NREM-REM sleep cycles were very similar during the baseline and caffeine sleep episodes (Figure 4a and b). As compared to the first cycle, indicated as $100 \%$, a progressive decrease in power density was observed in the $0.25-$ to $11-\mathrm{Hz}$ range, whereas in the frequency range of sleep spindles an increase was observed in later NREM sleep episodes. The time course of the caffeine effect on EEG power spectra was analyzed by comparing corresponding NREM sleep episodes of the baseline and caffeine condition (Figure 4c). The suppression of power density in the low frequency range $(0.25-5$
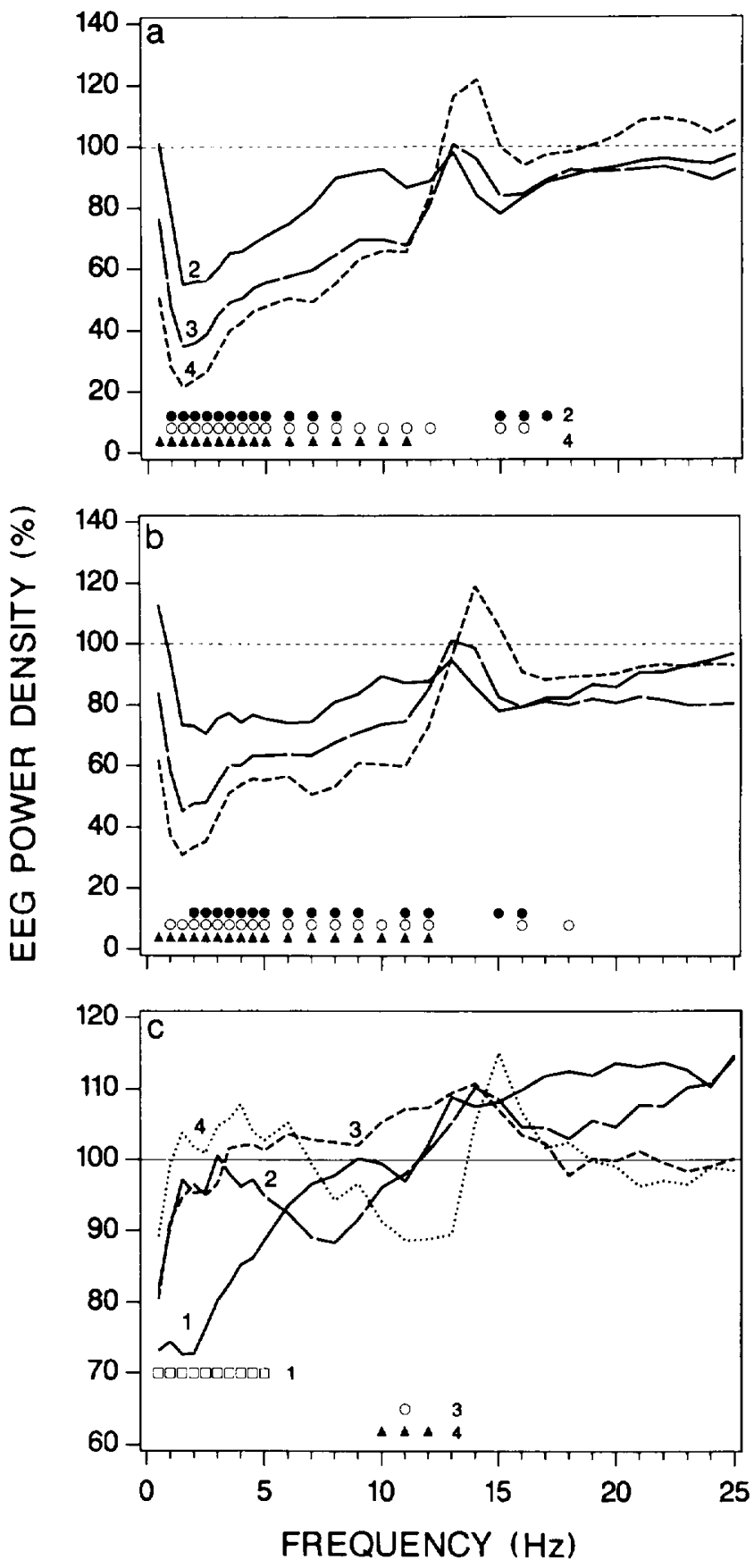

Figure 4. Changes in EEG (C3-A2 derivation) power density in NREM sleep over consecutive NREM sleep episodes during baseline $(a)$ and the caffeine sleep episode $(b)$. Values in panel $a$ and $b$ are expressed as a percentage of the values in the first NREM sleep episode of the baseline and the caffeine condition, respectively. Filled circles (episode 2), open circles (episode 3), and triangles (episode 4) indicate frequency bins for which power differed from the reference value $(p<.05$, paired $t$-test). The effects of caffeine on EEG power density are illustrated in panel $c$ where the values of the caffeine condition are expressed as percentage of the corresponding values in baseline. Open squares (episode 1), open circles (episode 3), and filled triangles (episode 4) indicate frequency bins for which power differed from the corresponding value in baseline ( $p<$ .05 , paired $t$-test). 
$\mathrm{Hz}$ ) was most prominent in the lowest bins $(0.25-2 \mathrm{~Hz})$ and was limited to the first NREM sleep episode.

To assess the influence of the pharmacokinetics, the change in SWA in the first NREM sleep episode or for the entire sleep episode was correlated with the halflife of caffeine estimated from the saliva levels. No significant correlations were obtained (first NREM sleep episode: $r^{2}=0.152$; entire sleep episode: $r^{2}=0.209$; $p>.4 ; n=5$; of the seven subjects participating in both the pharmacokinetics and the sleep study, technical difficulties precluded the half-life determination in two subjects).

\section{All-Night EEG Power Spectra during Caffeine and Postcaffeine Sleep Episode}

Compared to baseline, EEG power density during NREM sleep after caffeine intake was reduced in two bins of the low delta range and was enhanced in the frequency range of sleep spindles (Figure 5). In the postcaffeine sleep episode the values in NREM sleep were not significantly different from baseline.

Except for a reduction of power density in the 7.25to $8-\mathrm{Hz}$ bin during the caffeine sleep episode, no significant deviation from baseline was detected for REM sleep in either the caffeine or the postcaffeine night.

EEG Power Spectra in NREM Sleep in the First and Second Four Hours of the Caffeine and Postcaffeine Sleep Episodes: Topographical Aspects

During the first 4 hours of the caffeine sleep episode power density in the low delta range was suppressed in all derivations to a similar extent, although it did not reach significance in the occipital derivation (Figure 6). The ANOVA did not reveal a significant effect of the factor "derivation." The enhancement of power in the frequency range of sleep spindles was only significant in the central and parietal derivations. In the second 4 hours of the caffeine sleep episode, values in the delta and theta frequencies were close to baseline in all derivations, although in the central derivation a small but significant elevation was observed in the 3.75 to $6 \mathrm{~Hz}$ range. Significant reductions in the alpha and spindle frequency range were present in the parietal and occipital derivation.

\section{DISCUSSION}

One hundred milligram caffeine resulted in a saliva level of $7.5 \mu \mathrm{mol} / \mathrm{L} 65$ minutes after intake, which, in accordance with previous findings, corresponds to a plasma level of approximately $10 \mu \mathrm{mol} / \mathrm{L}$ (Bonati et al. 1982; Lie-

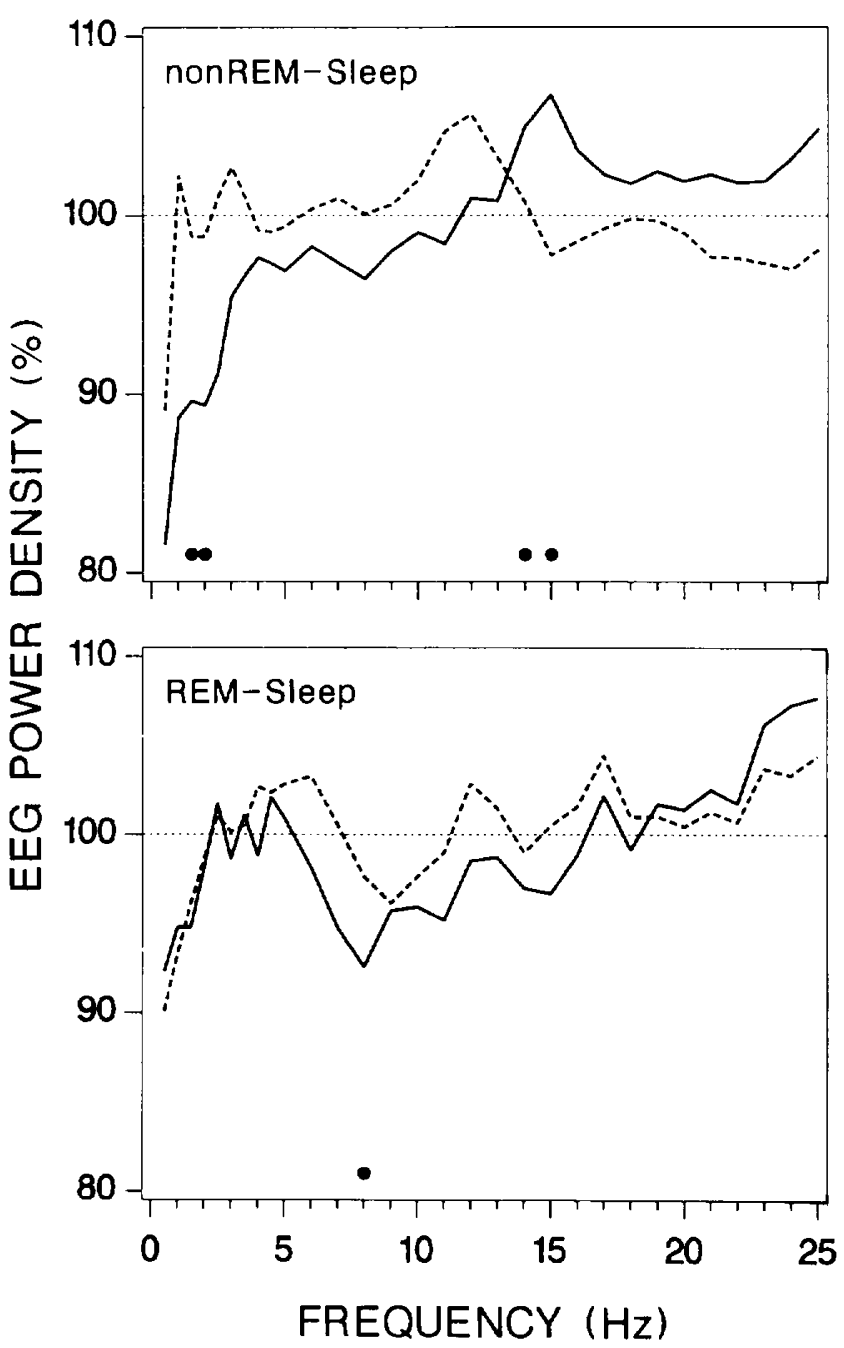

Figure 5. EEG power density in NREM sleep (upper panel) and REM sleep (lower panel) during the caffeine sleep episode (continuous line) and the postcaffeine sleep episode (interrupted line). All values are expressed as percentage of the corresponding values in baseline. Filled circles indicate frequency bins for which power in the sleep episode following caffeine intake differed significantly from the corresponding baseline values ( $p<.05$, paired $t$-test).

berman et al. 1987). This dose leads to a concentration in the cerebrospinal fluid of approximately $6 \mu \mathrm{mol} / \mathrm{L}$ (Soto et al. 1994). In this concentration range, caffeine antagonizes A1 and A2 receptors (Daly 1993). A 100$\mathrm{mg}$ dose of caffeine had significant effects on sleep and the sleep EEG, but not on heart rate. Even though caffeine was administered only a few minutes before lights out, sleep latency was prolonged. This effect is in accordance with a very rapid absorption of caffeine (Bonati et al. 1982), but has not been observed in a previous study (Nicholson and Stone 1980; 100-300 mg at lights out) in which sleep latency under placebo was considerably longer than in the present study. The absence of effects on REM sleep is consistent with previ- 

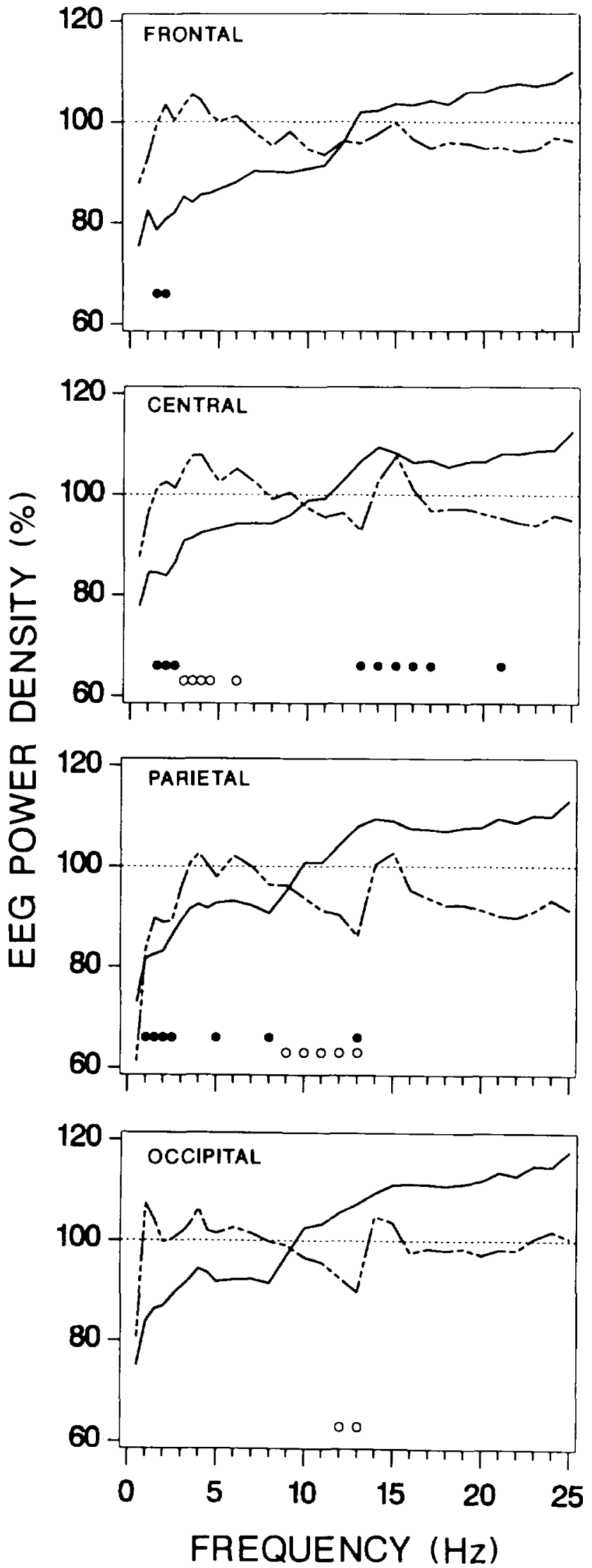

Figure 6. EEG power density in frontal, central, parietal, and occipital derivations during NREM sleep in the first (continuous line) and second 4 hours (interrupted line) of the caffeine sleep episode expressed as a percentage of the corresponding values in the baseline sleep episode. Filled circles (first 4-hour interval) and open circles (second 4-hour interval) indicate frequency bins in which power density differed significantly from corresponding value in baseline $(p<.05$, paired t-test). ous results (Karacan et al. 1976; Nicholson and Stone 1980).

Although caffeine caused only a minor disruption of sleep continuity as indexed by waking after sleep onset and sleep efficiency, the EEG in NREM sleep was significantly affected. Both visually scored stage 4 sleep and SWA were significantly reduced in the initial part of sleep. The analysis of the evolution of SWA demonstrated that this suppression was already present in the first 20 minutes after sleep onset. Another new finding was the slight enhancement of EEG activity in the frequency range of sleep spindles (Figure 5). In an earlier study, the quantification of spindle activity by an automatic spindle detector did not reveal a significant effect of caffeine (Hirshkowitz et al. 1982). The individual variability of the EEG changes did not appear to be associated with the variability in the pharmacokinetics (Figure 1). However, the sample was too small to permit any definitive statements.

The caffeine-induced changes in the EEG (i.e., the reduction of SWA and the enhancement of activity in the frequency range of sleep spindles) resembled only partially the changes observed during the gradual reduction of "sleep pressure" in the course of a normal sleep episode (Figure 4a) or in a sleep episode preceded by a nap (Dijk et al. 1989). Whereas in these physiological situations both delta and theta activity were deprominent in the lowest frequency bins of the delta band and did not extend to the theta band (Figures $4 a, 5$ ). These results do not support the notion that by antagonizing the action of adenosine in the brain, caffeine mimics the physiological reduction of "sleep pressure." Moreover, it is unlikely that the spectral changes were due to a subtle sleep disruption by caffeine, since during a selective slow-wave sleep suppression by acoustic stimuli, both delta and theta activity was reduced

If caffeine causes a pharmacological effect on the sleep EEG, it may be informative to compare it to other substances that have been shown to attenuate SWA. Benzodiazepine hypnotics and their analogues are wellknown for their suppressing action on SWA and their enhancement of sleep spindles. However, these changes creased, the suppression induced by caffeine was most (Dijk et al. 1987b; Dijk and Beersma 1989). 
are not predominant in the lowest delta range but encompass the entire delta and theta band (Borbély et al. 1983, 1985; Brunner et al. 1991; Dijk et al. 1989; Trachsel et al. 1990). Thus the caffeine spectrum clearly differs from the "spectral benzodiazepine signature" (Trachsel et al. 1990). Thus far, ethanol appears to be the only substance with a prominent and relatively selective effect on the lowest delta frequencies (Dijk et al. 1992). However, unlike caffeine, ethanol enhanced lowfrequency activity.

In the postcaffeine night, the level of SWA was higher than in the caffeine night but still below the baseline level. The difference from baseline could be due to the somewhat higher caffeine level prior to the postcaffeine night or to some as yet unaccounted for residual effect from the caffeine night.

We conclude that a modest dose of caffeine causes a suppression of SWA that is most prominent in the low delta frequency range, and a slight increase of EEG activity in the frequency range of sleep spindles. The data do not contradict the hypothesis that adenosine receptors are involved in the generation of slow waves. The pattern of the spectral changes differs to some extent from those induced by a physiological reduction of "sleep pressure." This may be related to the fact that caffeine exerts an antagonistic action on both $\mathrm{A} 1$ and $A 2$ receptors. The effects of the $A 1$ agonist PCA on the sleep EEG of the rat has been shown to correspond closely to those of an increased physiological "sleep pressure" (Benington et al. 1993). The simultaneous antagonistic effect of caffeine at both the $\mathrm{A} 1$ and $\mathrm{A} 2$ receptors may therefore be responsible for the differences of its effect on the EEG spectra from those induced by an attenuation of physiological sleep propensity.

\section{ACKNOWLEDGMENTS}

We thank Jörk Pischke and Beat Geering for programming assistance, Dr. K. Gautschi and Ms. S. Brogli for the determination of caffeine concentrations and Drs. Peter Achermann, Helen Driver, and Irene Tobler for their comments on the manuscript. This research was supported by the Swiss National Science Foundation Grant 31.32574.91.

\section{REFERENCES}

Benington JH, Kodali SK, Heller HC (1993): A1 adenosine receptor stimulation mimics changes in non-REM sleep EEG slow-wave activity produced by sleep deprivation in the rat. Sleep Res 22:4.

Biaggioni I, Saul S, Puckett A, Arzubiaga C (1991): Caffeine and theophylline as adenosine receptor antagonists in humans. J Pharmacol Exp Ther 258:588-593

Bonati M, Latini R, Galetti F, Young JF, Tognoni G, Garattini $S$ (1982): Caffeine disposition after oral doses. Clin Pharmacol Ther 32:98-106
Borbély AA, Tobler I, Hanagasioglu M (1984): Effect of sleep deprivation on sleep and EEG power spectra in the rat. Behav Brain Res 14:171-182

Borbély AA, Baumann F, Brandeis D, Strauch I, Lehmann D (1981): Sleep deprivation: Effect on sleep stages and EEG power density in man. Electroenceph Clin Neurophysiol 51:483-493

Borbély AA, Mattmann P, Loepfe M, Strauch I, Lehmann D (1985): Effect of benzodiazepine hypnotics on all-night sleep EEG spectra. Hum Neurobiol 4:189-194

Borbély AA, Mattmann P, Loepfe M, Fellmann I, Gerne M, Strauch I, Lehmann D (1983): A single dose of benzodiazepine hypnotics alters the sleep EEG in the subsequent drug-free night. Eur J Pharmacol 89:157-161

Brunner DP, Dijk DJ, Münch M, Borbély AA (1991): Effect of zolpidem on sleep and sleep EEG spectra in healthy young men. Psychopharmacology 104:1-5

Daly JW (1993): Mechanism of action of caffeine. In Garattini $\mathrm{S}$ (ed), Caffeine, Coffee, and Health, New York: Raven Press, pp 97-150

Dijk DJ, Beersma DGM (1989): Effects of SWS deprivation on subsequent EEG power density and spontaneous sleep duration. Electroencephalogr Clin Neurophysiol 72:312-320

Dijk DJ, Beersma DGM, Daan S (1987a): EEG power density during nap sleep: Reflection of an hourglass measuring the duration of prior wakefulness. J Biol Rhythms 2: 207-219

Dijk DJ, Beersma DGM, Daan S, Bloem GM, Van den Hoofdakker RH (1987b): Quantitative analysis of the effects of slow wave sleep deprivation during the first $3 \mathrm{~h}$ of sleep on subsequent EEG power density. Eur Arch Psychiatr Neurol Sci 236:323-328

Dijk DJ, Beersma DGM, Daan S, Van den Hoofdakker RH (1989): Effects of seganserin, a 5-HT2 antagonist, and temazepam on human sleep stages and EEG power spectra. Eur J Pharmacol 171:207-218

Dijk DJ, Brunner DP, Beersma DGM, Borbély AA (1990a): EEG power density and slow wave sleep as a function of prior waking and circadian phase. Sleep 13:430-440

Dijk DJ, Brunner DP, Borbély AA (1990b): Time course of EEG power density during long sleep in humans. Am J Physiol 258:R650-R661

Dijk DJ, Brunner DP, Aeschbach D, Tobler I, Borbély AA (1992): The effects of ethanol on human sleep EEG power spectra differ from those of benzodiazepine receptor agonists. Neuropsychopharmacology 7:225-232

Griffiths RR, Evans SM, Heishman SJ, Preston KL, Sannerud CA, Wolf B, Woodson PP (1990): Low-dose caffeine physical dependence in humans. J Pharmacol Exp Ther 255: 1123-1132

Haeckel R (1990): Relationship between intraindividual variation of the saliva/plasma- and of the arteriovenous concentration ratio as demonstrated by the administration of caffeine. J Clin Chem Clin Biochem 28:279-284

Haulica I, Ababei L, Brainişteanu D, Topoliceanu F (1973): Preliminary data on the possible hypnogenic role of adenosine. J Neurochem 21:1019-1020

Hirshkowitz M, Thornby JI, Karacan I (1982): Sleep spindles: Pharmacological effects in humans. Sleep 5:85-94 
Jasper HH (1958): Report on the committee on methods of clinical examination in electroencephalography. Electroencephalogr Clin Neurophysiol 10:370-375

Karacan I, Thornby JI, Anch AM, Booth GH, Williams RL, Salis PJ (1976): Dose-related sleep disturbances induced by coffee and caffeine. Clin Pharmacol Ther 20:682-689

Lieberman HR, Wurtman RJ, Emde GG, Roberts C, Coviella ILG (1987): The effects of low doses of caffeine on human performance and mood. Psychopharmacol 92: 308-312

Marley E, Nistico G (1972): Effects of catecholamines and adenosine derivatives given into brain of fowls. Br J Pharmacol 46:619-636

Nehlig A, Duval JL, Debry G (1992): Caffeine and the central nervous system: Mechanisms of action, biochemical, metabolic and psychostimulant effects. Brain Res Reviews 17:139-170

Nicholson AN, Stone BM (1980): Heterocyclic amphetamine derivatives and caffeine on sleep in man. Br J Clin Pharmacol 9:195-203

Oellerich M (1980): Enzyme immunoassays in clinical chemistry: Present status and trends. J Clin Chem Clin Biochem 18:197-208

Radulovacki M (1993): Adenosine sleep theory. Sleep Res 22:485

Radulovacki M, Miletich RS, Green RD (1982): N6(L-Phenylisopropyl)-adenosine (L-PIA) increases slow-wave sleep $\left(S_{2}\right)$ and decreases wakefulness in rats. Brain Res 246: 178-180

Radulovacki M, Virus RM, Djuricic-Nedelson M, Green RD (1983): Hypnotic effects of deoxycoformycin in rats. Brain Res 271:392-395

Rainnie DG, Grunze HCR, McCarley RW, Greene RW (1994): Adenosine inhibition of mesopontine cholinergic neurons: Implications for EEG arousal. Science 263:689-692

Rechtschaffen A, Kales A (1968): A Manual of Standardized
Terminology, Techniques and Scoring Systems for Sleep Stages of Human Subjects, Los Angeles: Brain Information Service/Brain Research Institute, pp 1-60

Sawynok J, Yaksh TL (1993): Caffeine as an analgesic adjuvant: A review of pharmacology and mechanism of action. Pharmacological Rev 45:43-85

Snel J (1993): Coffee and caffeine, sleep and wakefulness. In Garattini S (ed), Caffeine, Coffee, and Health, New York: Raven Press, pp 255-290

Snyder SH, Katims JJ, Annau Z, Bruns RF, Daly JW (1981): Adenosine receptors and behavioral actions of methylxanthines. Proc Natl Acad Sci U S A 78:3260-3264

Soto J, Sacristan JA, Alsar MJ (1994): Cerebrospinal fluid concentrations of caffeine following oral drug administration: Correlation with salivary and plasma concentrations. Ther Drug Monit 16:108-110

Steiger A, Trachsel L, Guldner J, Hemmeter U, Rothe B, Rupprecht R, Vedder H, Holsboer F (1993): Neurosteroid pregnenolone induces sleep-EEG changes in man compatible with inverse agonistic $\mathrm{GABA}_{\mathrm{A}}$-receptor modulation. Brain Res 615:267-274

Tobler I, Borbély AA (1990): The effect of 3-h and 6-h sleep deprivation on sleep and EEG spectra of the rat. Behav Brain Res 36:73-78

Trachsel L, Dijk DJ, Brunner DP, Klene C, Borbély AA (1990): Effect of zopiclone and midazolam on sleep and EEG spectra in a phase-advanced sleep schedule. Neuropsychopharmacology 3:11-18

Virus RM, Ticho S, Pilditch M, Radulovacki M (1990): A comparison of the effects of caffeine, 8-cyclopentyltheophylline, and alloxazine on sleep in rats: Possible roles of central nervous system adenosine receptors. Neuropsychopharmacology 3:243-249

Zylber-Katz E, Granit L, Levy M (1984): Relationship between caffeine concentrations in plasma and saliva. Clin Pharmacol Ther 36:133-137 